\title{
Intelligent Mobile Electronic Nose System Comprising a Hybrid Polymer-Functionalized Quartz Crystal Microbalance Sensor Array
}

Trisna Julian, Shidiq Nur Hidayat, Aditya Rianjanu, Agus Budi Dharmawan, Hutomo Suryo Wasisto,* and Kuwat Triyana*

Cite This: ACS Omega 2020, 5, 29492-29503

Read Online

ACCESS I

Llll Metrics \& More

Article Recommendations

Supporting Information

ABSTRACT: We devised a low-cost mobile electronic nose (e-nose) system using a quartz crystal microbalance (QCM) sensor array functionalized with various polymer-based thin active films (i.e., polyacrylonitrile, poly(vinylidene fluoride), poly(vinyl pyrrolidone), and poly(vinyl acetate)). It works based on the gravimetric detection principle, where the additional mass of the adsorbed molecules on the polymer surface can induce QCM resonance frequency shifts. To collect and process the obtained sensing data sets, a multichannel data acquisition (DAQ) circuitry was developed and calibrated using a function generator resulting in a device frequency resolution of $0.5 \mathrm{~Hz}$. Four prepared QCM sensors demonstrated various sensitivity levels with high reproducibility and consistency under exposure to seven different volatile organic compounds (VOCs). Moreover, two types of machine learning algorithms (i.e., linear discriminant analysis and support

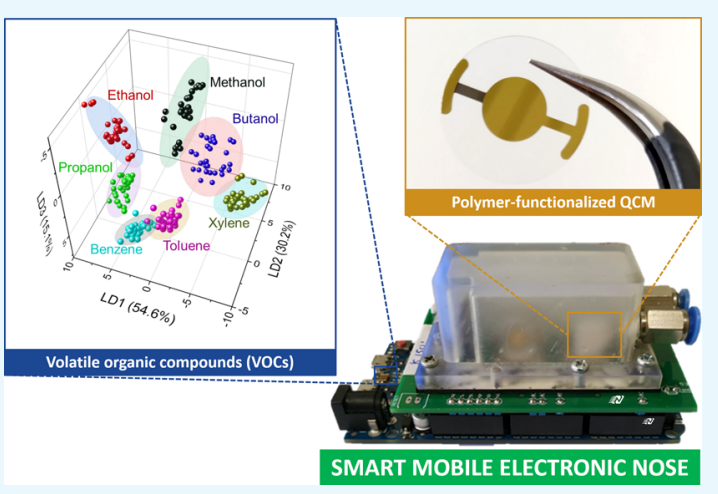
vector machine models) were employed to differentiate and classify those tested analytes, in which classification accuracies of up to 98 and $99 \%$ could be obtained, respectively. This high-performance e-nose system is expected to be used as a versatile sensing platform for performing reliable qualitative and quantitative analyses in complex gaseous mixtures containing numerous VOCs for early disease diagnosis and environmental quality monitoring.

\section{INTRODUCTION}

Electronic nose (e-nose) technology has been developed by scientists worldwide and greatly used in many application fields by mimicking and advancing the olfactory function of human beings, ${ }^{1}$ e.g., in medical care for noninvasive early disease diagnosis, ${ }^{2-4}$ food industry for product quality assurance, ${ }^{5-8}$ environmental monitoring for continuously online/in situ hazardous gas detection, ${ }^{9}$ and agriculture for plant protection $^{10-12}$ via monitoring and classification of volatile organic compounds (VOCs). An e-nose system consists normally of some or many gas sensors that are assembled into an array targeting different analytes, a so-called sensor array. Due to their broad selectivity and availability, commercial gas sensors based on metal-oxide semiconductors (MOSs) have often been utilized by many researchers as the main part of the e-nose sensor array. ${ }^{13-15}$ However, these sensors consume relatively high power (few hundreds of milliwatt) as they need to be activated at high temperatures during operation, limiting their implementation in a portable system. Moreover, they are normally sealed in a fixed housing. Hence, their active layer surfaces cannot be flexibly modified to adjust the sensitivity and selectivity toward target gases. ${ }^{16,17}$

Lately, low-power microlight plates have been developed using gallium nitride (GaN) light-emitting diode (LED) technology as photoactivated micropower gas sensors, ${ }^{18}$ where they could result in microwatt-range power consumption when combined with zinc oxide $(\mathrm{ZnO})$ nanoparticles as an active material for selective $\mathrm{NO}_{2}$ monitoring. ${ }^{19,20}$ Moreover, an innovative way toward efficient selfheating gas sensors was made by involving vertical $\mathrm{GaN}$ nanowire architectures that can be made in both two- and three-terminal device configurations. ${ }^{21-25}$ Despite their successful ultra-low-power demonstrations down to a few tens of microwatt, the sensors required complicated threedimensional (3D) cleanroom fabrication processes including many material deposition, filling, and etching steps, which led to higher device production costs. Thus, currently, highly selective and sensitive gas detectors with low power consumption, easy surface modification, and low fabrication costs are still demanded by sensor communities to be integrated into the e-nose system.

As an alternative to conductometric sensing (e.g., by chemoresistive sensors and field-effect transistors (FETs)),

Received: September 10, 2020

Accepted: October 21, 2020

Published: November 4, 2020 

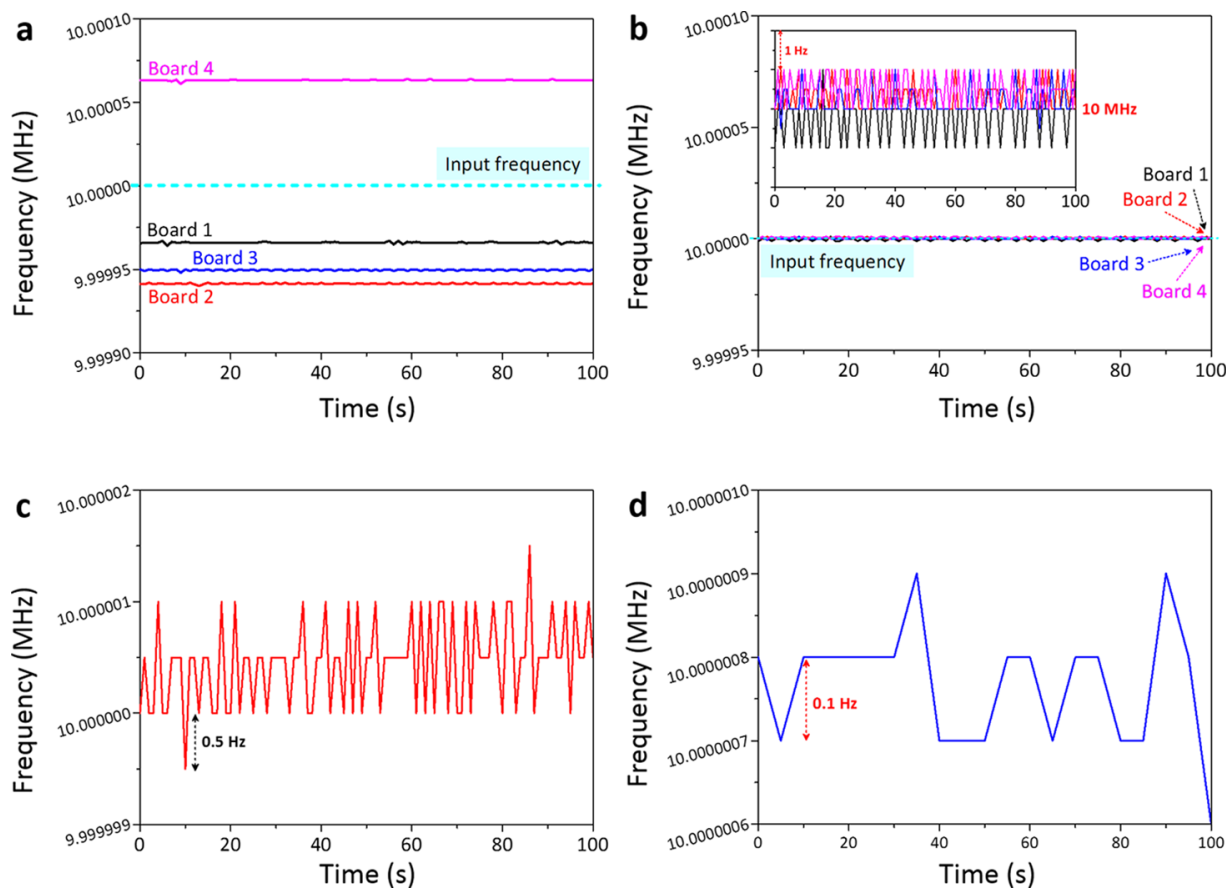

Figure 1. Frequency measured by four developed frequency counters (i.e., boards 1-4) (a) before and (b) after calibrations. The calibrated board 1 could obtain frequency resolutions of up to (c) 0.5 and (d) $0.1 \mathrm{~Hz}$ using gate times of 1 and $5 \mathrm{~s}$, respectively.

gravimetric detection has been continuously used and advanced taking advantage of device resonance frequency shifts induced by the additional mass of the adsorbed target analytes. Compared to the other dynamic gravimetric sensors like silicon resonant piezoresistive microcantilevers and vertical nanowire arrays that are very brittle, ${ }^{26-31}$ quartz crystal microbalance (QCM) platforms are preferable to be employed as gas sensors because they offer robust architecture, easy handling, a large sensing area, low power consumption, realtime detection, and low-cost fabrication. ${ }^{32-37}$ Furthermore, a QCM sensor can be easily functionalized by different coating methods (i.e., drop-casting, spin coating, electrospinning, chemical vapor deposition, and molecular imprinting) to tune its selectivity and sensitivity toward specific analytes. ${ }^{38-46}$ In terms of the active materials, both inorganic (e.g., metal oxides $\left(\mathrm{ZnO}, \mathrm{TiO}_{2}\right.$, and $\left.\mathrm{CuO}\right)$, graphene, and carbon nanotubes) and organic materials (e.g., polymers and polystyrene beads) have been employed as QCM sensing layers. ${ }^{47-54}$ Among these options, polymers (e.g., polyacrylonitrile (PAN), poly(vinyl acetate) (PVAc), poly(vinylidene fluoride) (PVDF), poly(vinyl pyrrolidone) (PVP), and their combinations) have attracted more attention due to their highly flexible adjustment of chemical and physical properties. Such substances can be made as either thin films by spin coating or nanofibrous mats by electrospinning. Here, although the nanofibers can offer a higher surface area to volume ratio than thin layers for sensing, a high voltage power supply (e.g., $5-20 \mathrm{kV}$ ) is still required to be involved during the fiber membrane creation, which is definitely not favorable if low power consumption has been a concern for the whole chain of sensor production and usage. The superiority of polymer as a gas-sensing layer is supported by the fact that its surface hydrophobicity and sensitivity can easily be modified by introducing other organic materials or dopants (e.g., chitosan and acids). ${ }^{42-44}$ This has led to an opportunity for such polymer-coated QCMs to be used for sensing either humidity (water molecule) or different gasses (e.g., safrole, alcohol, benzene, toluene, xylene, and ammonia). ${ }^{42,46,47}$ From our previous studies, PAN sensors were able to obtain high sensitivity and selectivity toward safrole, which is often found in alcoholic drinks and psychoactive recreational drugs (ecstasy). ${ }^{42}$ Meanwhile, PVAc-functionalized QCMs were used to measure the concentration of toxic gases such as benzene, toluene, and xylene. ${ }^{47}$ Furthermore, chitosanmodified cellulose acetate membranes were demonstrated to detect acetic anhydride, which is a carboxylic acid anhydride employed as an acetylating agent for alcohols. ${ }^{44}$

All these advantages have therefore attracted several e-nose developers to use QCM sensor arrays in their built-in systems. ${ }^{55-61}$ However, it is worth mentioning that previous research focused more on the optimization of the active layers; hence, the created setup still involved large and bulky tools such as conventional frequency counters and outsized chambers. Furthermore, a question on the feasibility of creating a handheld low-cost e-nose system with reliable qualitative and quantitative analysis capability and high classification performance has not been answered, as these devices were often deteriorated, caused by interferences (i.e., operating condition changes and hardware failures). ${ }^{62}$ In terms of data acquisition (DAQ) for QCM, a commercial device has already been offered by OpenQCM, Novaetech, Italy. ${ }^{63-65}$ However, it is limited only to a single-channel system. Thus, it is not suitable to be used directly for the e-nose device, where several QCM sensors in an array have to be brought into operation simultaneously. ${ }^{66,67}$

To circumvent all of the above issues, in this work, we developed a completely portable low-cost e-nose system by integrating a hybrid polymer-coated QCM sensor array with a custom-built calibrated multichannel DAQ circuitry and machine learning-based data analysis. Four different spincoated polymer thin films (i.e., PAN, PVAc, PVDF/PVAc, and PVP) were used resulting in different sensitivities toward 
Table 1. Characteristics of the Proposed E-Nose Data Acquisition (DAQ) System Compared to Previously Reported Devices

\begin{tabular}{|c|c|c|c|c|c|c|}
\hline reference & measuring device & dimension $(w \times l \times h)\left(\mathrm{mm}^{3}\right)$ & weight $(\mathrm{g})$ & channel number (\#) & $f_{\max }(\mathrm{MHz})$ & resolution $(\mathrm{Hz})$ \\
\hline 60 & QCM200 & $(270 \times 1829 \times 51)$ & 907 & 1 & 5 & 1.0 \\
\hline 69 & QCA 922 & $(260 \times 230 \times 88)$ & 200 & 4 & 10 & 0.1 \\
\hline 59 & NI-6602 (PCI) & & & 8 & 80 & 1.0 \\
\hline 70 & ASIC & & & 8 & 11 & 1.0 \\
\hline 68 & XC95108XL & & & 2 & 10 & 1.0 \\
\hline 71 & OpenQCM (Arduino Micro) & $(56 \times 48 \times 34)$ & 55 & 1 & 10 & 1.0 \\
\hline 67 & PIC16F628A & & & 4 & 10 & 1.0 \\
\hline this work & Arduino Due & $(70 \times 100 \times 45)$ & 110 & 4 & 21 & 0.5 \\
\hline
\end{tabular}
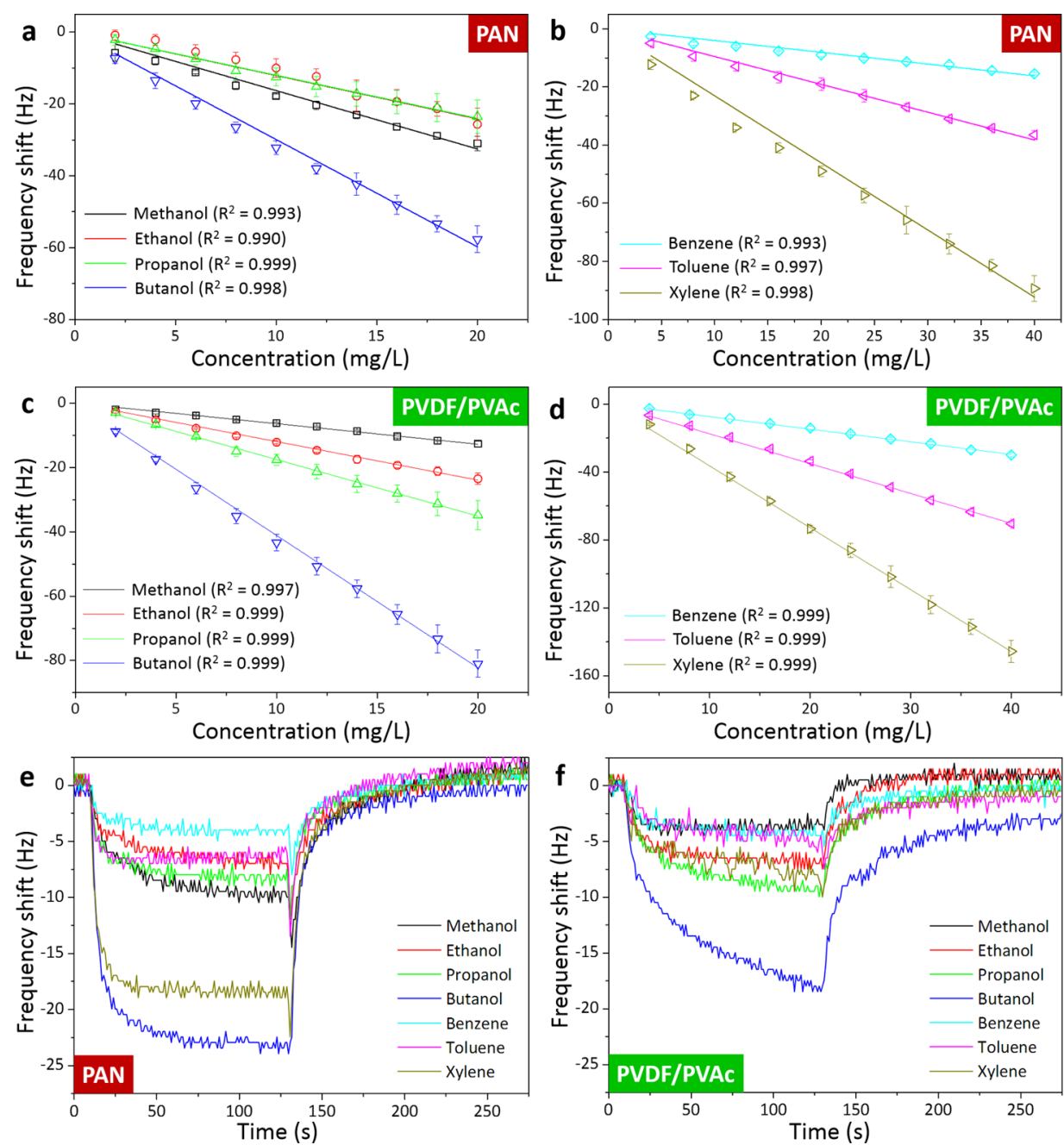

Figure 2. Frequency shifts of QCM sensors functionalized with ( $a, b)$ PAN and (c, d) PVDF/PVAc thin films under exposure to different volatile organic compounds (VOCs, i.e., methanol, ethanol, propanol, butanol, benzene, toluene, and xylene) at increasing concentrations of up to 20 and $40 \mathrm{mg} / \mathrm{L}$ for alcohol and BTX samples, respectively. Full-cycle dynamic responses of the QCM sensors functionalized with (e) PAN and (f) PVDF/PVAc thin films under influence of various VOCs at a concentration of $1 \mathrm{mg} / \mathrm{L}$. These QCMs belong to the sensor array inside the e-nose system.

various VOCs. Furthermore, to discriminate the obtained sensing data sets, two artificial intelligence models (i.e., linear discriminant analysis (LDA) and support vector machine $(\mathrm{SVM})$ ) were investigated during data analysis resulting in accurate analyte discrimination and classification.

\section{RESULTS AND DISCUSSION}

2.1. Data Acquisition System Characteristics. Accuracy is one of the most important characteristics of an instrument. To ensure the accuracy of our developed mobile e-nose system, it was first calibrated using a function generator (GW Instek AFG-2125) prior to sensing characterizations. A 10 $\mathrm{MHz}$ square wave with a DC bias of $1.65 \mathrm{~V}$ was supplied as an input to the frequency counter developed for e-nose. We investigated four different Arduino Due boards (i.e., boards 14) to evaluate their accuracies. From the conducted frequency measurements using a $10 \mathrm{MHz}$ input signal (Figure 1a), they yielded different measured frequencies. The frequency differences of up to $34,50,59$, and $63 \mathrm{~Hz}$ were found for boards $1-$ 4 , respectively, which indicated the inhomogeneity of the 

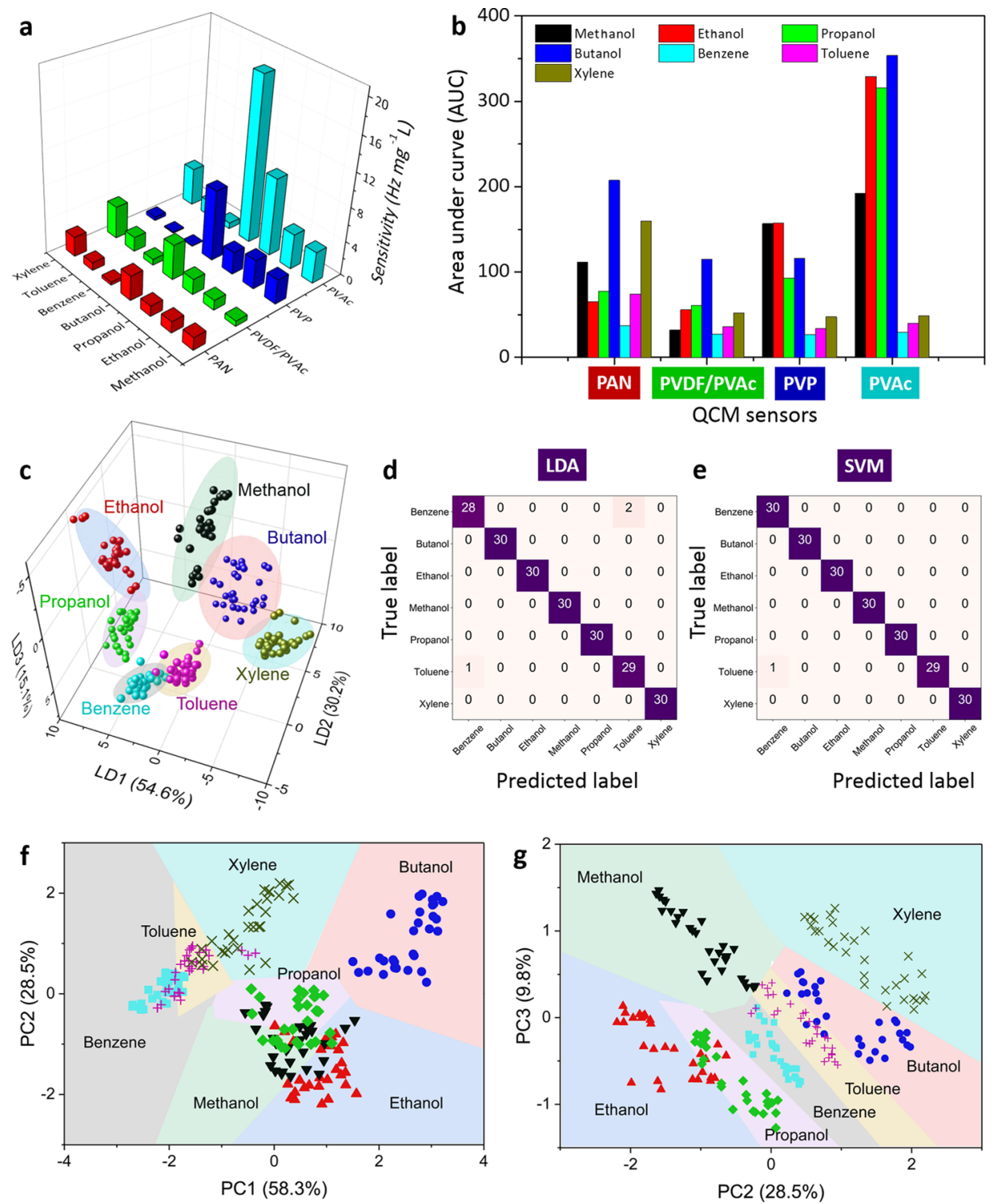

Figure 3. (a) Sensitivities of four QCM sensors coated with different polymers (i.e., PAN, PVDF/PVAc, PVP, and PVAc) exposed to various VOCs. (b) Area under the curve (AUC) profiles of sensing responses obtained with the QCM-based e-nose system. (c) Classification of seven different VOCs by the e-nose system using a linear discriminant analysis (LDA) model. Confusion matrix of the QCM-based e-nose performance using (d) LDA and (e) support vector machine (SVM) algorithms. The SVM-based decision region plots for (f) PC1 versus PC2 and (g) PC2 against PC3.

developed frequency counters. This inaccuracy issue might be attributed to different timer clocks of these four Arduino Due boards, which could then vary their time gating. The timer clock by default was set to the Arduino Due internal frequency that is $82 \mathrm{MHz}$ divided by two (i.e., $42 \mathrm{MHz}$ ). However, the internal frequency of Arduino Due could have deviations of up to $\pm 1.26 \mathrm{kHz}$ due to its crystal tolerance or ambient conditions. This would result in imprecise time gating.

Furthermore, to generate accurate $1 \mathrm{~s}$ time gating with an exact timer clock of $42 \mathrm{MHz}$, TCLK8 was needed to count 42000000 clocks. However, due to the deviation of internal frequency, the counter was required to count more or fewer clocks depending on the real timer clock. To overcome this problem, we measured the exact timer clock frequency and adjusted the minimum entailed clocks for TCLK8 for producing the most accurate time-gating results. Moreover, the temperature effect from the board was also investigated with respect to the frequency deviation (Figure S1 in the Supporting Information). After being calibrated, the measured frequencies of all four boards exhibit similar values to the given input frequency (see Figure $1 \mathrm{~b}$ ). Hence, the developed frequency counters have become reliable to measure the QCM frequencies. To further increase the counter accuracy, the built-in crystal could be replaced by a temperaturecompensated crystal oscillator (TCXO) ${ }^{68}$ From this point forward, the data shown in this paper are based on alreadycalibrated board 1 .

Besides device accuracy, we investigated the resolution of the developed frequency counter (board 1) using a $10 \mathrm{MHz}$ square wave to investigate the lowest possible limit of detection (LOD). In this case, device frequency resolutions of up to 0.5 and $0.1 \mathrm{~Hz}$ were achieved when gate times of 1 and $5 \mathrm{~s}$ were employed, respectively (see Figure 1c,d). Despite the resulting better resolution $(0.1 \mathrm{~Hz})$, the gate time of $5 \mathrm{~s}$ 
was not preferable for practical use. Therefore, from further investigation, we used $1 \mathrm{~s}$ gate time with a device resolution of $0.5 \mathrm{~Hz}$. A direct comparison of different gate times tested on the system can be seen in Figure S2. Table 1 lists several previously reported systems to be compared with the frequency counter developed in this work. It is obvious that our device can provide a high-performance multichannel frequency counter with a relatively small dimension and demonstrates better resolution among others. Moreover, with the $42 \mathrm{MHz}$ timer clock, our system is compatible with various QCM platforms having a maximum fundamental frequency $\left(f_{\max }\right)$ of up to $21 \mathrm{MHz}$. This specification opens the possibility of the device to be used in several different applications (i.e., gas sensors, humidity sensors, and e-nose systems).

2.2. Mobile Electronic Nose Performance. To investigate the performance of the developed e-nose system, we tested the integrated sensor array consisting of four QCMs with different coating polymer materials (i.e., PAN, PVDF/ PVAc, PVP, and PVAc). To obtain a high-performance system, different sensitivity levels toward analytes have to be obtained from each QCM sensor. The frequency shifts of all QCM sensors under the influence of various volatile organic compounds (VOCs) were monitored in a sensing system containing a sealed chamber equipped with a custom-made controlling program to record and transfer the measured data from the sensors to a personal computer. ${ }^{72,73}$ The concentrations of injected VOCs (both alcohol (i.e., methanol, ethanol, propanol, and butanol) and BTX samples (i.e., benzene, toluene, and xylene)) inside the chamber were calculated in $\mathrm{mg} / \mathrm{L}$ using their corresponding densities, purity percentages, and volumes. The ambient air was employed to refresh the chamber and desorb the analyte from the sensing layers.

Figure $2 a-d$ shows the typical resonance frequency shifts of the QCM sensors coated with PAN and PVDF/PVAc under exposure to various analytes. It is obvious that larger frequency shifts were yielded with increasing vapor concentrations for all samples. The sensors were tested for alcohol and BTX-based VOCs at concentrations of up to 20 and $40 \mathrm{mg} / \mathrm{L}$, respectively. Hence, 10 measurement data points could be obtained for all vaporized analytes. To acquire quantitative assessments, each measurement was repeated three times $(n=3)$ resulting in low standard deviation values $(0.2-6.7 \mathrm{~Hz})$, indicating that the produced devices possessed high sensing repeatability. Moreover, both sensors also revealed good linearity owing to their high determination coefficient (up to $R^{2}=0.999$ ). In terms of device sensitivity toward VOCs, the PVDF/PVAc-coated sensor exhibited the highest and lowest sensitivities of 4.1 and $0.6 \mathrm{~Hz} \mathrm{mg} / \mathrm{L}$ among other prepared QCMs, when exposed to butanol and methanol vapors, respectively. Meanwhile, the PAN-functionalized device reached the lowest sensitivity value of $0.4 \mathrm{~Hz} \mathrm{mg} / \mathrm{L}$ when tested with benzene vapor, implying that the sensors demonstrated different sensitivity levels depending on the employed active polymer layers. The measurement results of the other two sensors coated with PVP and PVAc show similar linear trends (see Figure S3 in the Supporting Information).

During full dynamic gas measurements, the sensor behavior was continuously monitored not only during its reaction to the injected vapors but also during its recovery when the chamber had been completely purged with air. Hence, both sensor response and recovery times could be identified. Figure 2e,f depicts full dynamic frequency cycles of two QCMs (i.e., PAN and PVDF/PVAc) under the influence of various tested analytes with the same concentration of $1 \mathrm{mg} / \mathrm{L}$. After the chamber was purged, the sensors could be fully recovered, which was indicated by the return of their resonance frequencies to the initial value. The response and recovery times of 6.3 and $9.3 \mathrm{~s}$, respectively, were demonstrated by the PAN-coated QCM when exposed to butanol vapors. Following the same procedure, 210 data sets were produced in total by four different QCM sensors (Figure S3 in the Supporting Information). These data were gathered from their responses to seven different VOCs, where the measurements of each analyte were repeated 30 times. The slight shape difference of the dynamic response curves depicted by all these four different materials could possibly be attributed to the altered homogeneities and surface conditions of the spin-coated polymers, which then affected the gas molecule adsorption and desorption processes. Moreover, it is well known that ambient temperature and relative humidity $(\mathrm{rH})$ can interfere with the gas sensor performance (i.e., resulting in undesirable QCM frequency shift). ${ }^{45,46}$ However, during VOC characterizations, these two parameters were kept at relatively stable values, in which typical changes of temperature and $\mathrm{rH}$ measured within $15 \mathrm{~min}$ were $<1{ }^{\circ} \mathrm{C}$ and $<1 \mathrm{rH} \%$, respectively. Thus, it was expected that they did not significantly influence the VOC measurements.

The sensitivities of all four sensors toward different VOCs are displayed in Figure 3a. Among them, the highest sensitivity of $20 \mathrm{~Hz} \mathrm{mg} / \mathrm{L}$ was exhibited by PVAc-coated QCM when exposed to butanol vapors. From our previous studies, a high affinity between the active polymer layer and the target analyte was found to be responsible for such highly sensitive polymerbased QCM sensors. The interaction between the active polymer thin films and vaporized analyte molecules (VOCs) could occur based on intermolecular interaction (e.g., hydrogen bonding, dipole-dipole interaction, and van der Waals adhesion).$^{74-76}$ For instance, PVP has been widely used as a sensing and capping agent material, which is assumed to be a hydrogen acceptor. ${ }^{74}$ While each ethanol molecule includes one $-\mathrm{OH}$ group, the PVP molecules possess numerous $\mathrm{C}=\mathrm{O}$ groups. Thus, when these ethanol and PVP molecules interact with each other, they could act as proton donors and receptors, respectively. A similar mechanism was applied to other polymers (e.g., PVAc films), where each subunit of the PVAc molecule has a carbonyl group that carries two oxygen atoms acting as a hydrogen acceptor. Each alcohol molecule consists of at least one hydroxyl functional group $(-\mathrm{OH})$, which can interact with a $\mathrm{C}=\mathrm{O}$ group in PVAc. Thus, again, the alcohol and PVAc molecules could act as proton donors and receptors, respectively, during their interaction. Besides intermolecular interaction, the ability of the analyte molecules to condense more naturally at a certain temperature might determine the sensing response. When the target molecules are easier to condense, they are adsorbed more on the film surfaces, resulting in a higher sensing signal. In other words, the VOC vapor pressures could also influence the sensitivity of polymer-based gas sensors. ${ }^{77,78}$ Moreover, as the integrated QCM sensors provided different degrees of sensitivity to the tested VOCs, they could be advantageous during their usage as a sensor array in the e-nose system. According to their area under the curve (AUC) signals in Figure $3 \mathrm{~b}$, the four QCM sensors have varied responses to different analytes, in which the lowest and highest profiles of 
Table 2. Performance Measurement Parameters (i.e., True Positive Rate (TPR), True Negative Rate (TNR), F1-Score, and Overall Accuracy) of the LDA and SVM Models Used by E-Nose to Classify the VOC Samples

\begin{tabular}{|c|c|c|c|c|c|c|c|c|}
\hline parameter & method & benzene & butanol & ethanol & methanol & propanol & toluene & xylene \\
\hline \multirow[t]{2}{*}{ TPR } & LDA & 0.93 & 1.00 & 1.00 & 1.00 & 1.00 & 0.97 & 1.00 \\
\hline & SVM & 1.00 & 1.00 & 1.00 & 1.00 & 1.00 & 0.97 & 1.00 \\
\hline \multirow[t]{2}{*}{ TNR } & LDA & 0.99 & 1.00 & 1.00 & 1.00 & 1.00 & 0.99 & 1.00 \\
\hline & SVM & 0.99 & 1.00 & 1.00 & 1.00 & 1.00 & 1.00 & 1.00 \\
\hline \multirow[t]{2}{*}{ F1-score } & LDA & 0.95 & 1.00 & 1.00 & 1.00 & 1.00 & 0.95 & 1.00 \\
\hline & SVM & 0.98 & 1.00 & 1.00 & 1.00 & 1.00 & 0.98 & 1.00 \\
\hline overall accuracy & SVM & 0.99 & & & & & & \\
\hline
\end{tabular}

26.63 and 353.81 were obtained by the benzene and butanol vapors, respectively. The sensitivity differences among response signals of each QCM sensor indicate that the QCM e-nose system has a good capability to discriminate different analytes.

Furthermore, supervised multivariate statistical methods (i.e., LDA and SVM) were used to verify system performance and to classify the vaporized samples. However, prior to this, an unsupervised learning algorithm of PCA was initially attempted to analyze and visualize the data distributions (see Figure S4 in the Supporting Information), in which, as a result, two large clusters can be identified (i.e., alcohol- and nonalcohol-based vapors). After all of the matrix data sets had been obtained, they were classified using LDA in Figure $3 c$, where three discriminant functions (LD1, LD2, and LD3) were investigated to evaluate the QCM-based e-nose performance. They explained $99.9 \%$ of the original data variability (i.e., 54.6, 30.2, and $15.1 \%$ for LD1, LD2, and LD3, respectively). They show that ethanol, propanol, methanol, butanol, and xylene have a clear discrimination area, while benzene and toluene are close to each other. Therefore, a cross-validation procedure (i.e., 10-fold cross-validation method) was then applied for evaluating the LDA model-based classification, in which its results are depicted in the e-nose confusion matrix (see Figure 3d). It obtained a mean accuracy of 0.98 and a standard deviation of 0.03 . Various tested analytes including ethanol, propanol, methanol, butanol, and xylene have $100 \%$ accuracy, while benzene and toluene samples exhibit three miss prediction cases. As a comparison, the SVM algorithm was also investigated for analyzing the QCM e-nose performance. The optimum SVM model of QCM e-nose was attained using hyperparameter tuning, where the $C$ values of $0.01,0.1,1.0$, $10.0,100.0$, and 1000.0 were set with the $\gamma$ values of 0.001 , $0.01,0.1,1.0,10.0,100.0$, and 1000.0, respectively. The kernel function was adjusted to linear and radial basis function (RBF). A 10-fold cross-validation method was again applied to reduce the overfitting issue, in which a $C$ value of 10.0 was selected with a linear kernel function, resulting in a confusion matrix, as shown in Figure 3e. Differentiating with those of the LDA model, higher mean accuracy and its standard deviation values of the SVM model could reach up to 0.99 and 0.01, respectively. In other words, the SVM model has demonstrated a high discrimination rate of up to $100 \%$ except for one data prediction mistake (i.e., between the true label of toluene and the predicted label of benzene). This has also emphasized that the LDA method was basically used as a baseline model to be compared with the SVM technique, which was the proposed classification method. Again, from Figure 3d,e, it is obvious that the SVM method delivers better results.
However, it should be noted that SVM cannot visualize the decision region for too many sensors. This is because the dimensions are exaggerated, resulting in the impossibility of visualizing a four-dimensional surface. Therefore, we used PCA score plots to illustrate the SVM decision regions (i.e., the decision functions used by SVM to determine the outcome of new data input), as shown in Figure 3f,g. In principle, PCA was employed for dimensionality reduction, in which it aimed at finding the directions of maximum variance in the highdimensional collected data and projecting them onto a new subspace with either equal or fewer dimensions than the original one. Using orthogonal transformation, different variables of principal components (PCs) can be defined. The PCs represent all of the variables. PC1 has the highest variability value, which indicates the most relevant information related to the raw data. This value of PC1 is followed by the lower values of the second (PC2) and third (PC3) variables, respectively. ${ }^{79}$ All of these express maximum margin between hyperplanes to obtain an intuitive understanding of their respective expressive power. Again, a clear separation was made among all samples by this SVM algorithm with a discrimination rate of $99 \%$ (10-fold cross-validation).

To further compare the two machine learning models employed (i.e., LDA and SVM models), Table 2 lists three important performance parameters, i.e., true positive rate (TPR), true negative rate (TNR), and F1-score for all VOCs. It is obvious that ethanol, propanol, methanol, butanol, and xylene have perfect TPR, TNR, and F1-score for both models. Meanwhile, for benzene and toluene, these parameters reached slightly higher values when e-nose was processed with the SVM model instead of the LDA model. Besides, to verify a significant level of both models, we used the $5 \times 2 \mathrm{CV} t$-test statistic method, in which a significant threshold of $\alpha=0.05$ was chosen for rejecting the null hypothesis. From the data calculation, a $t$-statistic value of -2.449 was obtained with a $p$ value of 0.058 . This has indicated that the null hypothesis cannot be rejected because $p$ has a slightly higher value than $\alpha$. As a result, it can be determined that both models can be employed in our e-nose as they have similar performances to discriminate seven different analytes. From the experimental results, regardless of the further possible sensitivity enhancement of the sensors by involving nanostructures as active layers, the currently developed system supported by simple machine learning algorithms could already answer the raised questions related to the feasibility of having a low-cost mobile e-nose but with smart analysis and highly accurate gas classification. 

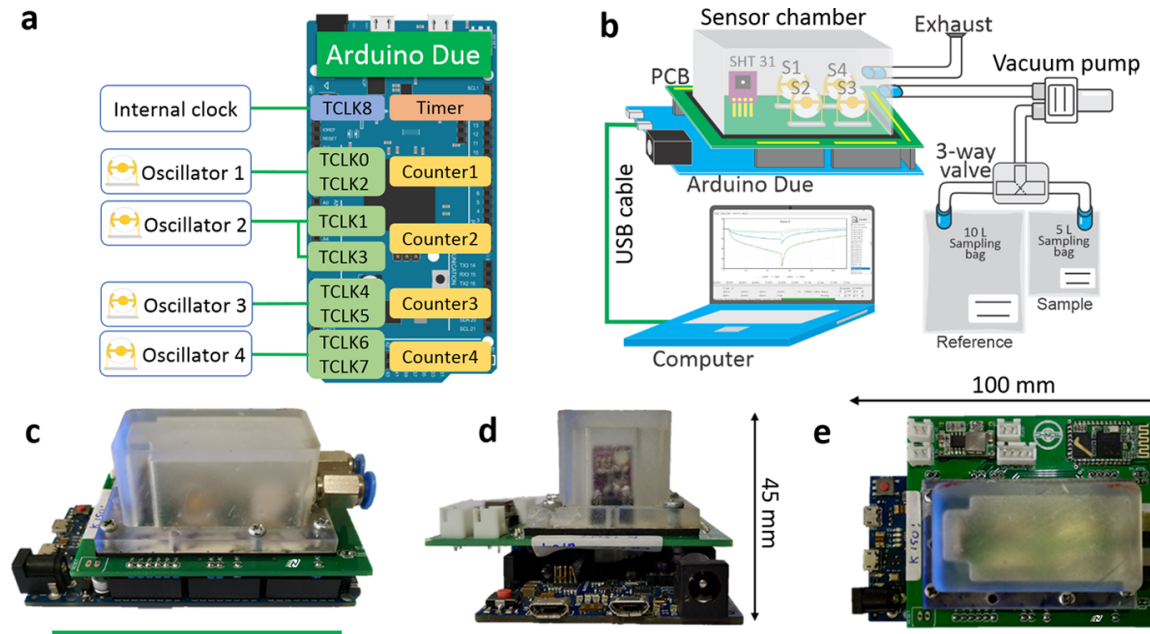

Mobile e-nose system

Side view

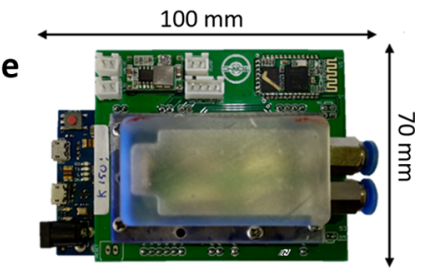

Top view

Figure 4. (a) Electronic schematic of the used oscillator circuit. (b) Gas measurement setup for characterizing the developed e-nose system. (c-e) Photographs of a mobile quartz crystal microbalance (QCM)-based electronic nose (e-nose) equipped with a data acquisition (DAQ) system.

\section{CONCLUSIONS}

A low-cost mobile electronic nose (e-nose) has been successfully devised by integrating a polymer thin-film-coated QCM sensor array and a customized Arduino Due data acquisition (DAQ) system. Four different coating materials (i.e., polyacrylonitrile (PAN), poly(vinylidene fluoride) (PVDF), poly(vinyl pyrrolidone) (PVP), and poly(vinyl acetate) (PVAc)) used as QCM active layers have resulted in different sensor sensitivities toward various volatile organic compounds (VOCs). From its performance evaluation, the enose system could provide high accuracy values of up to 98 and $99 \%$ to discriminate seven different types of VOC analytes when linear discriminant analysis (LDA) and support vector machine (SVM) models were employed, respectively. To further increase the sensitivity and selectivity of the sensors, their active layers can be modified as nanostructures like nanofibers for the next device generation, in which other membrane fabrication methods (e.g., electrospinning and molecular imprinting) can be opted. Despite the required performance optimization, the developed portable e-nose system exhibits a great potential for circumventing the issues faced by conventional bulky e-nose equipment (e.g., large size, static operation, poor analyte classification, and nonflexible sensor design); hence, this platform can be used in various odor monitoring applications where complex gas mixtures are involved.

\section{MATERIALS AND METHODS}

4.1. Mobile Electronic Nose System. For the developed mobile e-nose system, the proposed DAQ circuitries consist of two main parts (i.e., an oscillator and a frequency counter). The oscillator part comprises a crystal oscillator driver (SN74LVC1GX04), ${ }^{71}$ QCM array, and several passive components (i.e., capacitors and resistors). The oscillator circuit produces a square wave signal output that follows and tracks the QCM resonance frequency shift. The frequency counter was built using an Arduino Due development board embedded in a SAM3X8E microcontroller. It is basically a 32 bit timer counter with an adaptable microcontroller timer clock of up to $42 \mathrm{MHz}$, which can result in a frequency measurement capability of up to $21 \mathrm{MHz}$. Thus, various QCM platforms having a fundamental resonance frequency of $\leq 21 \mathrm{MHz}$ are compatible with the proposed e-nose system. Additionally, nine independent timer/counter channels are offered (i.e., TCLK0-TCLK8), leading to the feasibility of creating a multichannel frequency counter system.

Four pairs of frequency oscillators and counters were built in the proposed DAQ system, and their connections are illustrated in Figure 4a. The output signal produced from an oscillator was supplied to its corresponding frequency counter consisting of two timer channels, which are employed to count both falling and rising edges of the oscillator output signals. The linkage between the oscillator and the timer/counter channel was made possible by software (i.e., for counters 1, 3, and 4) and physical connection (i.e., for counter 2). Frequency measurements were performed by counting the total rising and falling edges that occurred during the gate time, in which the obtained value was then divided by a gate time and a constant value of two. The gate time was generated in the counter channel 8 (TCLK8) based on the timer clock of the microcontroller (i.e., $42 \mathrm{MHz}$ ).

The odor delivery system was created in a dynamic flow arrangement with two gas sampling bags having different volumes of 10 and $5 \mathrm{~L}$ to generate both reference and sample vapors, respectively (see Figure $4 \mathrm{~b}$ ). Initially, these bags were filled with dry air from the oil-less compressor. Then, analytes with a certain volume were exclusively injected into the $5 \mathrm{~L}$ sampling bag; hence, a concentration of $5 \mathrm{mg} / \mu \mathrm{L}$ of the analyte vapor could be reached. Both sampling bags were then placed in a normal room at a room temperature of $(30 \pm 1){ }^{\circ} \mathrm{C}$ for $5 \mathrm{~min}$ to ensure complete analyte evaporation. The sample and reference vapors were alternately introduced into the sensor chamber using a vacuum pump $(0.28 \mathrm{~L} / \mathrm{min})$. The vapor selection was made feasible by a three-way solenoid valve. During the gas measurement, the QCM resonance frequency value measured by DAQ was sent to the computer in real time in $1 \mathrm{~s}$ intervals.

Figure $4 c-e$ depicts the photographs of our developed mobile QCM-based e-nose equipped with a DAQ system, which is seen from the side and top views. The circuitries designed for controlling the four oscillators were jointly placed on a single printed circuit board (PCB), the so-called "Arduino shield". This compact design resulted in its convenient 
connection to the Arduino Due board. An HC49U QCM holder was used to support the flexibility of QCM replacement. A temperature and humidity sensor (Sensirion SHT31) was also added to real-time monitor the environmental parameters. Furthermore, a sensor chamber was custom-built using a stereolithography 3D printer, in which two pneumatic connectors were integrated into it as the chamber inlet and outlet. For the last parts, 10 bolt screws and a $1 \mathrm{~mm}$ thick rubber sheet were employed to assemble the PCB with the chamber and to ensure their proper airtight connection, respectively.

4.2. Hybrid Polymer-Functionalized QCM Sensor Array. Four different polymers of polyacrylonitrile (PAN, molecular weight $\left.\left(M_{\mathrm{w}}\right)=150000 \mathrm{~g} / \mathrm{mol}\right)$, poly (vinylidene fluoride) (PVDF, $M_{\mathrm{w}}=534000 \mathrm{~g} / \mathrm{mol}$ ), poly(vinyl pyrrolidone) (PVP, $\left.M_{\mathrm{w}}=1300000 \mathrm{~g} / \mathrm{mol}\right)$, and poly(vinyl acetate) (PVAc, $M_{\mathrm{w}}=140000 \mathrm{~g} / \mathrm{mol}$ ) were purchased from SigmaAldrich, Germany. The solvents (i.e., $N, N$-dimethylformamide (DMF) and acetone) were also obtained from Sigma-Aldrich, Germany. The tested analytes (i.e., methanol, ethanol, propanol, butanol, benzene, toluene, and xylene) were purchased from Merck, Germany. Benzene, toluene, and xylene are often abbreviated as BTX and considered hazardous compounds. ${ }^{80}$ The materials were used as received without any further purification process. The QCM sensors having $\sim 10$ $\mathrm{MHz}$ operating frequencies and gold electrodes were acquired from OpenQCM, Novaetech, Naples, Italy. They were equipped with HC 49-U QCM holders. Before being used in experiments, the QCM chips were precleaned using acetone and sonicated for $5 \mathrm{~min}$, followed by a drying process inside an electronic dry box for $30 \mathrm{~min}$.

The polymer solution was synthesized by dissolving the polymer powder at a specific concentration (see Table 3 ). It

Table 3. Parameters of Fabricated QCM Sensors with Their Frequency Shifts after Thin Polymer Film Depositions

\begin{tabular}{|c|c|c|c|c|}
\hline \multirow[b]{2}{*}{ material } & \multirow[b]{2}{*}{$\begin{array}{c}\text { concentration } \\
(\mathrm{w} / \mathrm{w} \%)\end{array}$} & \multicolumn{2}{|c|}{$\begin{array}{l}\text { spin parameters } \\
(\mathrm{rpm}: \mathrm{s})\end{array}$} & \multirow{2}{*}{$\begin{array}{l}\text { frequency shift } \\
\text { after loading } \\
(\mathrm{Hz})\end{array}$} \\
\hline & & $\omega_{1}: t_{1}$ & $\omega_{2}: t_{2}$ & \\
\hline PAN & 2 & $500: 10$ & $3000: 30$ & 3168 \\
\hline PVDF/PVAc & $(5 / 2)$ & 4000:5 & $6000: 15$ & 9303 \\
\hline PVP & 3 & $5000: 5$ & $6000: 30$ & 4532 \\
\hline PVAc & 16 & $1500: 10$ & $6000: 60$ & 9314 \\
\hline
\end{tabular}

was then stirred at a temperature of $60^{\circ} \mathrm{C}$ and a stirring speed of $1000 \mathrm{rpm}$ for $2 \mathrm{~h}$, resulting in a homogenous solution. From four different prepared polymers, three of them (i.e., PAN, PVP, and PVAc) were dissolved in dimethylformamide (DMF) solvent, while PVDF/PVAc sample was treated in a mixture of DMF/acetone with a ratio of $(1 / 1) \mathrm{v} / \mathrm{v}$. The thin-film fabrication process was performed by a two-step spin coating method utilizing a compact spin coater VTC-100. The first and second spin speeds are denoted as $\omega_{1}$ and $\omega_{2}$, respectively, while their durations are denoted as $t_{1}$ and $t_{2}$, respectively (see Table 3). The parameters were chosen based on the optimization. Prior to their use in exposure assessments, the polymer-coated QCMs were stored inside an electronic dry box for $24 \mathrm{~h}$.

4.3. Machine Learning. The signal data matrix consisting of four different QCM sensor signals was generated by the enose with a data rate of $1 \mathrm{~Hz}$. In this case, 280 time series data were produced from each sensor with delay, sampling, and purging times of 10,120 , and $150 \mathrm{~s}$, respectively. Thus, considering all four integrated QCMs, a total number of 1120 data values were available as the initial matrix data set for further processing. A feature extraction method of the area under the curve (AUC) was applied to the raw data matrix in a preprocessing procedure to improve the accuracy of a multivariate statistical model. Hence, important information can be extracted from the signals, while redundant data can be reduced. For $i$-sensor and $j$-sample, AUC values can be described as follows

$$
\operatorname{AUC}_{i, j}=\int_{t=a}^{t=b}\left[f_{i . j}(0)-f_{i, j}(t)\right] \mathrm{d} t
$$

where $f_{i, j}(0), f_{i, j}(\mathrm{t}), a$, and $b$ are the baseline frequency, the time-dependent frequency, the initial boundary set time (at the $10 \mathrm{~s}$ time series), and the final boundary set time (at the $110 \mathrm{~s}$ time series), respectively.

After preprocessing, the final matrix data set consisted of four sensors with 210 AUC values for all assays (i.e., 7 different analytes with 30 data for each of them). A resampling method of $k$-fold cross-validation was used to evaluate the model performance for predicting the unseen data. With $k=10,10 \%$ of the data were employed for internal validation purposes, in which the overfitting issue was minimized. During their implementation, data were scaled and centered.

First, a supervised multivariate statistical method of linear discriminant analysis (LDA) was applied for evaluating signal data gathered by the QCM e-nose to classify seven different analytes. For machine learning and pattern-classification applications, the LDA model was normally employed as a technique for dimensionality reduction and classification at the preprocessing stage. In addition to the LDA model, an SVM algorithm was also applied to QCM e-nose data processing as a comparison, in which this machine learning technique was suitable for handling linear and nonlinear data with complex pattern recognition problems. ${ }^{10}$ SVM uses a quadratic hyperplane optimization to discriminate the classes and a kernel function to optimize its performance based on a linear, polynomial, or radial basis function. A grid search procedure with a 10-fold cross-validation method was applied for hyperparameter tuning. The procedure finds the most optimum SVM parameters (i.e., cost $(C)$ and $\gamma$ values) to maximize performance and reduce overfitting issues. For evaluation purpose, an accuracy metric was used that was calculated as

$$
\text { accuracy }=\frac{\mathrm{TP}+\mathrm{TN}}{\mathrm{TP}+\mathrm{TN}+\mathrm{FP}+\mathrm{FN}}
$$

where TP, TN, FP, and FN are true positive, true negative, false positive, and false negative, respectively.

For evaluating the performance of both LDA and SVM models, a statistical method of $5 \times 2 \mathrm{cv}$ paired $t$-test, which was previously proposed by Dietterich, ${ }^{81}$ was applied. The data set was randomly divided into two parts (i.e., training data (50\%) and testing data $(50 \%))$ and then rotated between train and test. This procedure was unsystematically repeated five times. Applying $t$-statistic, it approximately follows a $t$-distribution with 5 degrees of freedom. The $p$-value can be computed using $t$-statistic and compared with a previously chosen significance level (e.g., $\alpha=0.05$ ). If the $p$-value is larger than $\alpha$, the null hypothesis cannot be rejected, unless these two models have equal performance or exhibit only a slight difference. In terms 
of the developed software, a block diagram shown in Figure S5 can explain the flow of the developed chemometric method used in our e-nose. Here, it is clear that the LDA was used as the baseline model. Meanwhile, the proposed classification model of SVM was employed after the data were first processed with principal component analysis (PCA) to investigate their variability. In the end, evaluation using 10fold cross-validation was applied to the results from both LDA and SVM to obtain and compare their accuracy scores.

\section{ASSOCIATED CONTENT}

\section{SI Supporting Information}

The Supporting Information is available free of charge at https://pubs.acs.org/doi/10.1021/acsomega.0c04433.

Temperature effect on the data acquisition system; comparison of different gate times for the data acquisition system; frequency measurement results of polymer-coated QCM sensors; principal component analysis; and block diagram of the chemometric method used in mobile e-nose (PDF)

\section{AUTHOR INFORMATION}

\section{Corresponding Authors}

Hutomo Suryo Wasisto - Institute of Semiconductor Technology (IHT) and Laboratory for Emerging Nanometrology (LENA), Technische Universität Braunschweig, Braunschweig 38106, Germany; 이이.org/0000-00024522-3625; Email: h.wasisto@tu-braunschweig.de

Kuwat Triyana - Department of Physics, Faculty of Mathematics and Natural Sciences and Institute of Halal Industry and System (IHIS), Universitas Gadjah Mada, Yogyakarta 55281, Indonesia; 이이.orid.org/000-0002-14664364; Email: triyana@ugm.ac.id

\section{Authors}

Trisna Julian - Department of Physics, Faculty of Mathematics and Natural Sciences, Universitas Gadjah Mada, Yogyakarta 55281, Indonesia; PT. Nanosense Instrument Indonesia, Yogyakarta 55167, Indonesia

Shidiq Nur Hidayat - Department of Physics, Faculty of Mathematics and Natural Sciences, Universitas Gadjah Mada, Yogyakarta 55281, Indonesia; PT. Nanosense Instrument Indonesia, Yogyakarta 55167, Indonesia

Aditya Rianjanu - Department of Materials Engineering and Research and Innovation Center for Advanced Materials, Institut Teknologi Sumatera, Jati Agung, Lampung 35365, Indonesia; 1 orcid.org/0000-0001-7852-3619

Agus Budi Dharmawan - Institute of Semiconductor Technology (IHT) and Laboratory for Emerging Nanometrology (LENA), Technische Universität Braunschweig, Braunschweig 38106, Germany; Faculty of Information Technology, Universitas Tarumanagara, Jakarta 11440, Indonesia

Complete contact information is available at:

https://pubs.acs.org/10.1021/acsomega.0c04433

\section{Author Contributions}

T.J. developed and characterized the electronic nose (e-nose) system, fabricated hybrid polymer-QCMs, conducted gassensing measurements, analyzed and validated the data, wrote the initial draft, and edited the paper manuscript. S.N.H. created control software for data acquisition and analyzed the data using machine learning algorithms. A.R. analyzed the data, wrote the initial draft, and edited the paper. A.B.D. analyzed the machine learning algorithms and their results. H.S.W. validated the methods, analyzed the data, wrote the initial draft, revised the paper, acquired the research funding, and led the project. K.T. validated the methods, managed the funding and resources, led the project, and revised the paper. All authors have approved the final manuscript.

\section{Notes}

The authors declare no competing financial interest.

All data generated or analyzed during this study are included in this published article (and its Supporting Information file).

\section{ACKNOWLEDGMENTS}

This work was partially funded by the Ministry of Research, Technology and National Research Innovation Agency of the Republic of Indonesia (KEMENRISTEK/BRIN) through a research scheme of "Penelitian Terapan Unggulan Perguruan Tinggi” (PTUPT) 2020 under contract number 1896/UN1/ DITLIT/DIT-LIT/PT/2020. H.S.W. acknowledges financial support from the Lower Saxony Ministry of Science and Culture (N-MWK), Germany, for the LENA-OptoSense group and the Indonesian Ministry of Research, Technology and Higher Education (KEMENRISTEKDIKTI) for the Indonesian-German Center for Nano and Quantum Technologies (IG-Nano) at Technische Universität Braunschweig, Germany. A.B.D. thanks KEMENRISTEKDIKTI and Indonesia Endowment Fund for Education (LPDP) for his PhD scholarship (Beasiswa Unggulan Dosen Indonesia Luar Negeri (BUDILN) under ref S-1205/LPDP.3/2017). H.S.W. and K.T. thank the Directorate General of Higher Education, Science, and Technology Resources (Ditjen SDID) and KEMENRISTEKDIKTI for providing them an opportunity to be involved in an excellent Indonesian diaspora platform of World-Class Scholar Symposium (Simposium Cendekia Kelas Dunia (SCKD)), which has led to the establishment of continuous collaboration between domestic and diaspora scientists for accelerating the transfer of science and technology and advancing research and development in Indonesia, especially in the fields of nanotechnology and sensors.

\section{REFERENCES}

(1) Hu, W.; Wan, L.; Jian, Y.; Ren, C.; Jin, K.; Su, X.; Bai, X.; Haick, H.; Yao, M.; Wu, W. Electronic Noses: From Advanced Materials to Sensors Aided with Data Processing. Adv. Mater. Technol. 2018, 4, No. 1800488.

(2) Li, W.; Liu, H.; Xie, D.; He, Z.; Pi, X. Lung Cancer Screening Based on Type-Different Sensor Arrays. Sci. Rep. 2017, 7, No. 1969.

(3) Peng, G.; Tisch, U.; Adams, O.; Hakim, M.; Shehada, N.; Broza, Y. Y.; Billan, S.; Abdah-Bortnyak, R.; Kuten, A.; Haick, H. Diagnosing Lung Cancer in Exhaled Breath Using Gold Nanoparticles. Nat. Nanotechnol. 2009, 4, 669-673.

(4) Wilson, A. Application of Electronic-Nose Technologies and VOC-Biomarkers for the Noninvasive Early Diagnosis of Gastrointestinal Diseases. Sensors 2018, 18, 2613.

(5) Hidayat, S. N.; Triyana, K.; Fauzan, I.; Julian, T.; Lelono, D.; Yusuf, Y.; Ngadiman, N.; Veloso, A. C. A.; Peres, A. M. The Electronic Nose Coupled with Chemometric Tools for Discriminating the Quality of Black Tea Samples In Situ. Chemosensors 2019, 7, 29.

(6) Sabilla, S.; Sarno, R.; Triyana, K. Optimizing Threshold Using Pearson Correlation for Selecting Features of Electronic Nose Signals. Int. J. Intell. Eng. Syst. 2019, 12, 81-90. 
(7) Wojnowski, W.; Majchrzak, T.; Dymerski, T.; Gębicki, J.; Namieśnik, J. Electronic Noses: Powerful Tools in Meat Quality Assessment. Meat Sci. 2017, 131, 119-131.

(8) Hidayat, S. N.; Triyana, K. Optimized Back-Propagation Combined with Radial Basic Neural Network for Improving Performance of the Electronic Nose: Case Study on the Fermentation Process of Tempeh. AIP Conf. Proc. 2016, 1755, No. 020001.

(9) Capelli, L.; Sironi, S.; et al. Electronic Noses for Environmental Monitoring Applications. Sensors 2014, 14, 19979-20007.

(10) Hidayat, S.; Rusman, A.; Julian, T.; Triyana, K.; Veloso, A.; Peres, A. Electronic Nose Coupled with Linear and Nonlinear Supervised Learning Methods for Rapid Discriminating Quality Grades of Superior Java Cocoa Beans. Int. J. Intell. Eng. Syst. 2019, 12, $167-176$.

(11) Zhang, H.; Wang, J. Detection of Age and Insect Damage Incurred by Wheat, with an Electronic Nose. J. Stored Prod. Res. 2007, 43, 489-495.

(12) Kiani, S.; Minaei, S.; Ghasemi-Varnamkhasti, M. Application of Electronic Nose Systems for Assessing Quality of Medicinal and Aromatic Plant Products: A Review. J. Appl. Res. Med. Aromat. Plants 2016, 3, 1-9.

(13) Gancarz, M.; Wawrzyniak, J.; Gawrysiak-Witulska, M.; Wiącek, D.; Nawrocka, A.; Tadla, M.; Rusinek, R. Application of Electronic Nose with MOS Sensors to Prediction of Rapeseed Quality. Measurement 2017, 103, 227-234.

(14) Sanaeifar, A.; Mohtasebi, S. S.; Ghasemi-Varnamkhasti, M.; Ahmadi, H. Application of MOS Based Electronic Nose for the Prediction of Banana Quality Properties. Measurement 2016, 82, 105114.

(15) Xu, K.; Wang, J.; Wei, Z.; Deng, F.; Wang, Y.; Cheng, S. An Optimization of the MOS Electronic Nose Sensor Array for the Detection of Chinese Pecan Quality. J. Food Eng. 2017, 203, 25-31.

(16) Park, S. Y.; Kim, Y.; Kim, T.; Eom, T. H.; Kim, S. Y.; Jang, H. W. Chemoresistive Materials for Electronic Nose: Progress, Perspectives, and Challenges. InfoMat 2019, 1, 289-316.

(17) Ji, H.; Zeng, W.; Li, Y. Gas Sensing Mechanisms of Metal Oxide Semiconductors: A Focus Review. Nanoscale 2019, 11, 22664-22684.

(18) Wasisto, H. S.; Prades, J. D.; Gülink, J.; Waag, A. Beyond SolidState Lighting: Miniaturization, Hybrid Integration, and Applications of GaN Nano- and Micro-LEDs. Appl. Phys. Rev. 2019, 6, No. 041315.

(19) Casals, O.; Markiewicz, N.; Fabrega, C.; Gràcia, I.; Cané, C.; Wasisto, H. S.; Waag, A.; Prades, J. D. A Parts Per Billion (Ppb) Sensor for NO 2 with Microwatt (MW) Power Requirements Based on Micro Light Plates. ACS Sens. 2019, 4, 822-826.

(20) Markiewicz, N.; Casals, O.; Fabrega, C.; Gràcia, I.; Cané, C.; Wasisto, H. S.; Waag, A.; Prades, J. D. Micro Light Plates for LowPower Photoactivated (Gas) Sensors. Appl. Phys. Lett. 2019, 114, No. 053508.

(21) Fatahilah, M. F.; Strempel, K.; Yu, F.; Vodapally, S.; Waag, A.; Wasisto, H. S. 3D GaN Nanoarchitecture for Field-Effect Transistors. Micro Nano Eng. 2019, 3, 59-81.

(22) Fatahilah, M. F.; Yu, F.; Strempel, K.; Römer, F.; Maradan, D.; Meneghini, M.; Bakin, A.; Hohls, F.; Schumacher, H. W.; Witzigmann, B.; et al. Top-down GaN Nanowire Transistors with Nearly Zero Gate Hysteresis for Parallel Vertical Electronics. Sci. Rep. 2019, 9, No. 10301.

(23) Mariana, S.; Gülink, J.; Hamdana, G.; Yu, F.; Strempel, K.; Spende, H.; Yulianto, N.; Granz, T.; Prades, J. D.; Peiner, E.; et al. Vertical GaN Nanowires and Nanoscale Light-Emitting-Diode Arrays for Lighting and Sensing Applications. ACS Appl. Nano Mater. 2019, 2, 4133-4142.

(24) Markiewicz, N.; Casals, O.; Fatahilah, M. F.; Xu, J.; Schmidt, A.; Wasisto, H. S.; Peiner, E.; Waag, A.; Prades, J. D. Ultra Low Power Mass-Producible Gas Sensor Based on Efficient Self-Heated GaN Nanorods. In 2019 20th International Conference on Solid-State Sensors, Actuators and Microsystems \& Eurosensors XXXIII (TRANSDUCERS \& EUROSENSORS XXXIII), IEEE: 2019; pp 1321-1324.

(25) Yu, F.; Strempel, K.; Fatahilah, M. F.; Zhou, H.; Romer, F.; Bakin, A.; Witzigmann, B.; Schumacher, H. W.; Wasisto, H. S.; Waag,
A. Normally Off Vertical 3-D GaN Nanowire MOSFETs With Inverted $p$-GaN Channel. IEEE Trans. Electron Devices 2018, 65, 2439-2445.

(26) Wasisto, H. S.; Merzsch, S.; Stranz, A.; Waag, A.; Uhde, E.; Salthammer, T.; Peiner, E. Silicon Nanowire Resonators: Aerosol Nanoparticle Mass Sensing in the Workplace. IEEE Nanotechnol. Mag. 2013, 7, 18-23.

(27) Wasisto, H. S.; Zhang, Q.; Merzsch, S.; Waag, A.; Peiner, E. A Phase-Locked Loop Frequency Tracking System for Portable Microelectromechanical Piezoresistive Cantilever Mass Sensors. Microsyst. Technol. 2014, 20, 559-569.

(28) Merzsch, S.; Steib, F.; Wasisto, H. S.; Stranz, A.; Hinze, P.; Weimann, T.; Peiner, E.; Waag, A. Production of Vertical Nanowire Resonators by Cryogenic-ICP-DRIE. Microsyst. Technol. 2014, 20, 759-767.

(29) Wasisto, H. S.; Merzsch, S.; Stranz, A.; Waag, A.; Uhde, E.; Salthammer, T.; Peiner, E. Femtogram Aerosol Nanoparticle Mass Sensing Utilising Vertical Silicon Nanowire Resonators. Micro Nano Lett. 2013, 8, 554-558.

(30) Wasisto, H. S.; Huang, K.; Merzsch, S.; Stranz, A.; Waag, A.; Peiner, E. Finite Element Modeling and Experimental Proof of NEMS-Based Silicon Pillar Resonators for Nanoparticle Mass Sensing Applications. Microsyst. Technol. 2014, 20, 571-584.

(31) Wasisto, H. S.; Steib, F.; Merzsch, S.; Waag, A.; Peiner, E. Vertical Silicon Nanowire Array-Patterned Microcantilever Resonators for Enhanced Detection of Cigarette Smoke Aerosols. Micro Nano Lett. 2014, 9, 676-679.

(32) Ren, X.; Zhang, D.; Wang, D.; Li, Z.; Liu, S. Quartz Crystal Microbalance Sensor for Humidity Sensing Based on Layer-by-Layer Self-Assembled PDDAC/Graphene Oxide Film. IEEE Sens. J. 2018, 18, 9471-9476.

(33) Zhang, D.; Wang, D.; Wang, D.; Wu, Z. Polypyrrole-Modified Tin Disulfide Nanoflower-Based Quartz Crystal Microbalance Sensor for Humidity Sensing. IEEE Sens. J. 2019, 19, 9166-9171.

(34) Anju, V. P.; Jithesh, P. R.; Narayanankutty, S. K. A Novel Humidity and Ammonia Sensor Based on Nanofibers/Polyaniline/ Polyvinyl Alcohol. Sens. Actuators, A 2019, 285, 35-44.

(35) Zhang, D.; Chen, H.; Zhou, X.; Wang, D.; Jin, Y.; Yu, S. In-Situ Polymerization of Metal Organic Frameworks-Derived ZnCo2O4/ Polypyrrole Nanofilm on QCM Electrodes for Ultra-Highly Sensitive Humidity Sensing Application. Sens. Actuators, A 2019, 295, 687-695.

(36) Triyana, K.; Rianjanu, A.; Nugroho, D. B.; As'ari, A. H.; Kusumaatmaja, A.; Roto, R.; Suryana, R.; Wasisto, H. S. A Highly Sensitive Safrole Sensor Based on Polyvinyl Acetate (PVAc) Nanofiber-Coated QCM. Sci. Rep. 2019, 9, No. 15407.

(37) Roto, R.; Rianjanu, A.; Fatyadi, I. A.; Kusumaatmaja, A.; Triyana, K. Enhanced Sensitivity and Selectivity of Ammonia Sensing by QCM Modified with Boric Acid-Doped PVAc Nanofiber. Sens. Actuators, A 2020, 304, No. 111902.

(38) Zhao, Q.; He, Z.; Jiang, Y.; Yuan, Z.; Wu, H.; Su, C.; Tai, H. Enhanced Acetone-Sensing Properties of PEI Thin Film by GO-NH2 Functional Groups Modification at Room Temperature. Front. Mater. 2019, 5, 82

(39) Saha, T.; Guo, N. Q.; Ramakrishnan, N. Zinc Oxide Nanostructure-Based Langasite Crystal Microbalance Ultraviolet Sensor. IEEE Sens. J. 2016, 16, 2964-2970.

(40) Zhang, D.; Chen, H.; Li, P.; Wang, D.; Yang, Z. Humidity Sensing Properties of Metal Organic Framework-Derived Hollow Ball-Like TiO2 Coated QCM Sensor. IEEE Sens. J. 2019, 19, 29092915.

(41) Chen, W.; Deng, F.; Xu, M.; Wang, J.; Wei, Z.; Wang, Y. GO/ Cu2O Nanocomposite Based QCM Gas Sensor for Trimethylamine Detection under Low Concentrations. Sens. Actuators, B 2018, 273, 498-504.

(42) Rianjanu, A.; Triyana, K.; Nurbaiti, N.; Hasanah, S. A.; Kusumaatmaja, A.; Roto, R. An Enhanced Safrole Sensing Performance of a Polyacrylonitrile Nanofiber- Based-QCM Sensor by Overlaying with Chitosan. Sains Malaysiana 2019, 48, 2041-2049. 
(43) Bayram, A.; Özbek, C.; Şenel, M.; Okur, S. CO Gas Sorption Properties of Ferrocene Branched Chitosan Derivatives. Sens. Actuators, B 2017, 241, 308-313.

(44) Nugroho, D. B.; Rianjanu, A.; Triyana, K.; Kusumaatmaja, A.; Roto, R. Quartz Crystal Microbalance-Coated Cellulose Acetate Nanofibers Overlaid with Chitosan for Detection of Acetic Anhydride Vapor. Results Phys. 2019, 15, No. 102680.

(45) Julian, T.; Rianjanu, A.; Hidayat, S. N.; Kusumaatmaja, A.; Roto, R.; Triyana, K. Quartz Crystal Microbalance Coated with PEDOT-PSS/PVA Nanofiber for a High-Performance Humidity Sensor. J. Sens. Sens. Syst. 2019, 8, 243-250.

(46) Rianjanu, A.; Julian, T.; Hidayat, S. N.; Yulianto, N.; Majid, N.; Syamsu, I.; Wasisto, H. S.; Triyana, K. Quartz Crystal Microbalance Humidity Sensors Integrated with Hydrophilic PolyethyleneimineGrafted Polyacrylonitrile Nanofibers. Sens. Actuators, B 2020, 319, No. 128286

(47) Rianjanu, A.; Hasanah, S. A.; Nugroho, D. B.; Kusumaatmaja, A.; Roto, R.; Triyana, K. Polyvinyl Acetate Film-Based Quartz Crystal Microbalance for the Detection of Benzene, Toluene, and Xylene Vapors in Air. Chemosensors 2019, 7, 20.

(48) Tai, H.; Bao, X.; He, Y.; Du, X.; Xie, G.; Jiang, Y. Enhanced Formaldehyde-Sensing Performances of Mixed PolyethyleneimineMultiwalled Carbon Nanotubes Composite Films on Quartz Crystal Microbalance. IEEE Sens. J. 2015, 15, 6904-6911.

(49) Bhattacharyya Banerjee, M.; Pradhan, S.; Banerjee Roy, R.; Tudu, B.; Das, D. K.; Bandyopadhyay, R.; Pramanik, P. Detection of Benzene and Volatile Aromatic Compounds by Molecularly Imprinted Polymer-Coated Quartz Crystal Microbalance Sensor. IEEE Sens. J. 2019, 19, 885-892.

(50) Yang, M.; He, J.; Hu, X.; Yan, C.; Cheng, Z. CuO Nanostructures As Quartz Crystal Microbalance Sensing Layers for Detection of Trace Hydrogen Cyanide Gas. Environ. Sci. Technol. 2011, 45, 6088-6094.

(51) Zhao, Q.; Duan, Z.; Yuan, Z.; Li, X.; Si, W.; Liu, B.; Zhang, Y.; Jiang, Y.; Tai, H. High Performance Ethylene Sensor Based on Palladium-Loaded Tin Oxide: Application in Fruit Quality Detection. Chin. Chem. Lett. 2020, 31, 2045-2049.

(52) Tai, H.; Duan, Z.; He, Z.; Li, X.; Xu, J.; Liu, B.; Jiang, Y. Enhanced Ammonia Response of Ti3C2Tx Nanosheets Supported by TiO2 Nanoparticles at Room Temperature. Sens. Actuators, B 2019, 298, No. 126874.

(53) Tai, H.; Wang, S.; Duan, Z.; Jiang, Y. Evolution of Breath Analysis Based on Humidity and Gas Sensors: Potential and Challenges. Sens. Actuators, B 2020, 318, 128104.

(54) Tai, H.; Duan, Z.; Wang, Y.; Wang, S.; Jiang, Y. Paper-Based Sensors for Gas, Humidity, and Strain Detections: A Review. ACS Appl. Mater. Interfaces 2020, 12, 31037-31053.

(55) Zhang, D.; Wang, D.; Li, P.; Zhou, X.; Zong, X.; Dong, G. Facile Fabrication of High-Performance QCM Humidity Sensor Based on Layer-by-Layer Self-Assembled Polyaniline/Graphene Oxide Nanocomposite Film. Sens. Actuators, B 2018, 255, 18691877.

(56) Zhang, D.; Liu, J.; Jiang, C.; Liu, A.; Xia, B. Quantitative Detection of Formaldehyde and Ammonia Gas via Metal OxideModified Graphene-Based Sensor Array Combining with Neural Network Model. Sens. Actuators, B 2017, 240, 55-65.

(57) Saraoglu, H. M.; Selvi, A. O.; Ebeoglu, M. A.; Tasaltin, C. Electronic Nose System Based on Quartz Crystal Microbalance Sensor for Blood Glucose and Hbalc Levels from Exhaled Breath Odor. IEEE Sens. J. 2013, 13, 4229-4235.

(58) Li, Q.; Gu, Y.; Wang, N. Application of Random Forest Classifier by Means of a QCM-Based E-Nose in the Identification of Chinese Liquor Flavors. IEEE Sens. J. 2017, 17, 1788-1794.

(59) Sharma, P.; Ghosh, A.; Tudu, B.; Sabhapondit, S.; Baruah, B. D.; Tamuly, P.; Bhattacharyya, N.; Bandyopadhyay, R. Monitoring the Fermentation Process of Black Tea Using QCM Sensor Based Electronic Nose. Sens. Actuators, B 2015, 219, 146-157.
(60) Escuderos, M. E.; Sánchez, S.; Jiménez, A. Quartz Crystal Microbalance (QCM) Sensor Arrays Selection for Olive Oil Sensory Evaluation. Food Chem. 2011, 124, 857-862.

(61) Jha, S. K.; Hayashi, K. Polyacrylic Acid Polymer and Aldehydes Template Molecule Based MIPs Coated QCM Sensors for Detection of Pattern Aldehydes in Body Odor. Sens. Actuators, B 2015, 206, 471-487.

(62) Liang, Z.; Tian, F.; Yang, S.; Zhang, C.; Sun, H.; Liu, T. Study on Interference Suppression Algorithms for Electronic Noses: A Review. Sensors 2018, 18, 1179.

(63) Wilson, C.; Lukowicz, R.; Merchant, S.; Valquier-Flynn, H.; Caballero, J.; Sandoval, J.; Okuom, M.; Huber, C.; Brooks, T. D.; Wilson, E. et al. Quantitative and Qualitative Assessment Methods for Biofilm Growth: A Mini-Review Res. Rev. J. Eng. Technol. 2017, 64.

(64) Turkdogan, S. Bandgap Engineered II-VI Quaternary Alloys and Their Humidity Sensing Performance Analyzed by QCM. J. Mater. Sci. Mater. Electron. 2019, 30, 10427-10434.

(65) Zainuddin, A. A.; Nordin, A. N.; Rahim, R.; Ralib, A. A.; Khan, S.; Guines, C.; Chatras, M.; Pothier, A. Verification of Quartz Crystal Microbalance Array Using Vector Network Analyzer and OpenQCM. Indones. J. Electr. Eng. Comput. Sci. 2018, 10, 84.

(66) Muckley, E. S.; Anazagasty, C.; Jacobs, C. B.; Hianik, T.; Ivanov, I. N. Low-Cost Scalable Quartz Crystal Microbalance Array for Environmental Sensing. Organic Sensors and Bioelectronics IX; International Society for Optics and Photonics: 2016; Vol. 9944, p 99440Y.

(67) Karapınar, M.; Gürkan, S.; Öner, P. A.; Doğan, S. Design of a Multi-Channel Quartz Crystal Microbalance Data Acquisition System. Meas. Sci. Technol. 2018, 29, No. 075009.

(68) Sakti, S. Dual Channel High Precision 26 Bit Frequency Counter Using CPLD XC95108XL for QCM Sensor System. Int. J. Inf. Electron. Eng. 2014, 4, 239-243.

(69) Seiko, E. C. L. Crystal Resonator Chemistry Measurement System Model: QCA922.

(70) Beeley, J. M.; Mills, C.; Hammond, P. A.; Glidle, A.; Cooper, J. M.; Wang, L.; Cumming, D. R. S. All-Digital Interface ASIC for a QCM-Based Electronic Nose. Sens. Actuators, B 2004, 103, 31-36.

(71) openQCM. openQCM.

(72) Triyana, K.; Sembiring, A.; Rianjanu, A.; Hidayat, S.; Riowirawan, R.; Julian, T.; Kusumaatmaja, A.; Santoso, I.; Roto, R. Chitosan-Based Quartz Crystal Microbalance for Alcohol Sensing. Electronics 2018, 7, 181.

(73) Rianjanu, A.; Roto, R.; Julian, T.; Hidayat, S.; Kusumaatmaja, A.; Suyono, E.; Triyana, K. Polyacrylonitrile Nanofiber-Based Quartz Crystal Microbalance for Sensitive Detection of Safrole. Sensors 2018, 18,1150 .

(74) Aria, M. M.; Irajizad, A.; Astaraei, F. R.; Shariatpanahi, S. P.; Sarvari, R. Ethanol Sensing Properties of PVP Electrospun Membranes Studied by Quartz Crystal Microbalance. Measurement 2016, 78, 283-288.

(75) Jia, Y.; Chen, L.; Yu, H.; Zhang, Y.; Dong, F. Graphene Oxide/ Polystyrene Composite Nanofibers on Quartz Crystal Microbalance Electrode for the Ammonia Detection. RSC Adv. 2015, 5, 4062040627.

(76) Yang, M.; He, J. A Copper-Manganese Composite Oxide as QCM Sensing Layers for Detection of Formaldehyde Gas. RSC Adv. 2018, 8, 22-27.

(77) Rianjanu, A.; Triyana, K.; Nugroho, D. B.; Kusumaatmaja, A.; Roto, R. Electrospun Polyvinyl Acetate Nanofiber Modified Quartz Crystal Microbalance for Detection of Primary Alcohol Vapor. Sens. Actuators, A 2020, 301, No. 111742.

(78) Roto, R.; Rianjanu, A.; Rahmawati, A.; Fatyadi, I. A.; Yulianto, N.; Majid, N.; Syamsu, I.; Wasisto, H. S.; Triyana, K. Quartz crystal microbalances functionalized with citric acid-doped polyvinyl acetate nanofibers for ammonia sensing. ACS Appl. Nano Mater. 2020, 3, $5687-5697$

(79) Tazi, I.; Triyana, K.; Siswanta, D.; Veloso, A. C. A.; Peres, A. M.; Dias, L. G. Dairy Products Discrimination According to the Milk 
Type Using an Electrochemical Multisensor Device Coupled with Chemometric Tools. J. Food Meas. Charact. 2018, 12, 2385-2393.

(80) Edokpolo, B.; Yu, Q.; Connell, D. Health Risk Assessment of Ambient Air Concentrations of Benzene, Toluene and Xylene (BTX) in Service Station Environments. Int. J. Environ. Res. Public Health 2014, 11, 6354-6374.

(81) Dietterich, T. G. Approximate Statistical Tests for Comparing Supervised Classification Learning Algorithms. Neural Comput. 1998, 10, 1895-1923. 